Research Paper

\title{
Low Frequency of the ERG Oncogene Alterations in Prostate Cancer Patients from India
}

\author{
Sudhir Rawal ${ }^{1}$, Denise Young, ${ }^{2}$ Molly Williams ${ }^{2,3}$, Monica Colombo ${ }^{2,3}$, Raghunath Krishnappa ${ }^{4}$, Gyorgy \\ Petrovics ${ }^{2}$, David G. McLeod ${ }^{2,3}$, Shiv Srivastava ${ }^{2,}{ }^{凶}$ and Isabell A. Sesterhenn ${ }^{5}$ \\ 1. Rajiv Gandhi Cancer Institute and Research Centre, New Delhi, India. \\ 2. Center for Prostate Disease Research, Department of Surgery, Uniformed Services University of the Health Sciences, Rockville, Mary- \\ land, USA. \\ 3. Urology Service, Walter Reed National Military Medical Center, Bethesda, Maryland, USA. \\ 4. Bangalore Institute of Oncology - HCG, Bangalore, India. \\ 5. Department of Genitourinary Pathology, Joint Pathology Center, Silver Spring, Maryland, USA.
}

$\square$ Corresponding author: Shiv Srivastava, PhD; ssrivastava@cpdr.org.

(c) Ivyspring International Publisher. This is an open-access article distributed under the terms of the Creative Commons License (http://creativecommons.org/ licenses/by-nc-nd/3.0/). Reproduction is permitted for personal, noncommercial use, provided that the article is in whole, unmodified, and properly cited.

Received: 2013.04.26; Accepted: 2013.05.28; Published: 2013.07.05

\begin{abstract}
Introduction and Objective: ERG oncogene fusions (predominantly TMPRSS2-ERG) represent the most common (50-70\% frequency) and validated prostate cancer ( $\mathrm{CaP})$ genome alteration in the Western countries. A common TMPRSS2-ERG fusion type leads to the androgen dependent tumor cell specific expression of the TMPRSS2-ERG fusion transcript and amino terminally truncated ERG oncoprotein. CaP prevalence and aggressiveness, as well as genomic alterations vary in different geographic locations in the world. Recent studies from our group highlighted significantly lower frequency of ERG alterations in prostate index tumors of African American men ( $30 \%)$ in comparison to Caucasian Americans ( 60\%). Further, much lower frequencies (10 $-25 \%$ ) of ERG alterations have been reported in studies from China and Japan. There is no study on ERG alterations in CaP patients from India, representing a significant portion of the world male population. This study focuses on the frequency of ERG oncoprotein expression in $\mathrm{CaP}$ patients from India.

Methods: De-identified formalin-fixed paraffin-embedded (FFPE) specimens from radical prostatectomy (RP) specimens of $5 \mathrm{I}$ patients from the Rajiv Gandhi Cancer Institute and Research Centre (RGCl), New Delhi, India, were analyzed for ERG alterations. The ERG oncoprotein expression as a surrogate of ERG gene fusions was analyzed by using a highly specific ERG monoclonal antibody (9FY). TMPRSS2-ERG fusion was assessed by fluorescent in situ hybridization (FISH) assays using the break-apart ERG probes.

Results: Specimens reflecting prior hormonal treatment, or lacking any tumor content, were excluded from the analyses. Of the thirty evaluable specimens, ERG positive tumors were present in 8 cases $(27 \%)$ and one tumor specimen exhibited rare ERG positive cells. None of the benign glands were positive for ERG supporting previous studies showing complete specificity of the ERG oncoprotein for detection of tumors cells in prostate.

Conclusions: Frequency of ERG oncoprotein expression is much lower in $\mathrm{CaP}$ patients from India in comparison to higher frequency of ERG alterations noted in Western countries. ERG frequency in Indian $\mathrm{CaP}$ is similar to observations from Japan and China. Since ERG oncogenic activation is a promising biomarker and therapeutic target for CaP, careful evaluation of ERG is needed in CaP patients from different parts of the world.
\end{abstract}

Key words: prostate cancer, ERG oncogene, India. 


\section{Introduction}

Prostate cancer $(\mathrm{CaP})$ remains the most common non-skin cancer of men and the second leading cause of cancer deaths in the USA ${ }^{1}$. CaP is the fifth most common cancer in the world in both sexes and second most common in men after melanoma ${ }^{2}$. CaP prevalence and aggressiveness, as well as genomic alterations, vary in different geographic locations in the world with it being most prevalent in Caucasians and least prevalent among Asians 3,4 . According to the World Health Organization GLOBOCAN data from 2008, the highest regional incidence is in Australia and New Zealand $(104.2$ per 100,000$)$ and the lowest in South-Central Asia $(4.1 \text { per } 100,000)^{2}$. The incidence in India has been steadily increasing by approximately $10 \%$ from 1978 to $1997^{4}$ and in 2008 was 3.7 per 100,000 , with a mortality rate of 2.5 per $100,000^{2}$. It is also noted that a much higher percentage of the $\mathrm{CaP}$ is detected in the advanced stages which is likely due to the lack of wide spread use of $\mathrm{CaP}$ screening.

TMPRSS2-ERG gene fusion leading to ERG over expression represents a highly prevalent oncogenic alteration $(50-70 \%)$ in $\mathrm{CaP}$ patients from Western countries $^{5-11}$. ERG gene fusions often involve regulatory sequences of the androgen receptor (AR) responsive genes (predominantly TMPRSS2) and protein coding sequences of nuclear transcription factors of the ETS gene family (predominantly ERG) ${ }^{12-16}$. These gene fusions lead to unscheduled androgen dependent expression of ETS related transcription factors in tumor cell specific manner ${ }^{17}$. Extensive evaluations of ERG alterations at genome, transcript and protein levels demonstrate unprecedented specificity of ERG fusions for detecting prostate tumor cells ${ }^{14-17}$. Studies focusing on the oncogenic functions of ERG point to its involvement in: abrogating differentiation; facilitating cell invasion and epithelial to mesenchymal transition; and disrupting epigenetic, inflammatory and DNA damage control mechanisms 14-17. Therapeutic targeting of ERG or ERG interacting proteins, such as PARP, hold promise in developing new strategies for the treatment of $\mathrm{CaP}^{18,19}$. In summary multi-pronged evaluations of the ERG in CaP continue to reflect the critical causal role of this prevalent oncogenic activation in CaP.

Our recent report ${ }^{20}$ using a matched cohort of $\mathrm{CaP}$ cases showed a significantly lower frequency of ERG alterations in African Americans (28\%) in comparison to Caucasian Americans (63\%) 21,22. A much lower frequency of ERG (7.5-28\%) alteration has also been reported in studies from China and Japan 21,23,24,25. There is no study on ERG alterations in CaP patients from India, representing a significant portion of the world population. This study focused on the frequency of ERG oncoprotein expression in $\mathrm{CaP}$ pa- tients from India.

\section{Materials and Methods}

\section{Prostate Specimens}

De-identified formalin-fixed, paraffin-embedded specimens from RP specimens of 51 patients from RGCI, New Delhi, India, were analyzed. The specimens were collected from 2003-2008 under an International Institutional Review Board-approved protocol.

\section{Immunohistochemistry (IHC) Assay for ERG oncoprotein expression}

Evaluation of the ERG oncoprotein expression in prostate tissues was performed as described previously $^{26}$. Briefly, four $\mu \mathrm{m}$ sections were taken from the specimens that were deparaffinized, dehydrated and blocked in $0.6 \%$ hydrogen peroxide in methanol for 20 min. The sections were then microwaved in EDTA ( $\mathrm{pH} \mathrm{8.0)}$ for $30 \mathrm{~min}$. and cooled for $30 \mathrm{~min}$. at room temperature in EDTA buffer. The sections were then blocked in $1 \%$ horse serum for $40 \mathrm{~min}$. and were incubated with the ERG-MAb mouse monoclonal antibody (9FY, available from Biocare Medical Inc.) at a dilution of 1:1280 for $60 \mathrm{~min}$. at room temperature. Sections were incubated with the biotinylated horse anti-mouse antibody at a dilution of 1:200 (Vector Laboratories, Burlingame, CA) for $30 \mathrm{~min}$. followed by treatment with the ABC Kit (Vector Laboratories, Burlingame, CA) for $30 \mathrm{~min}$. The color was developed by VIP (Vector Laboratories, Burlingame, CA) treatment for $5 \mathrm{~min}$. and the sections were counterstained by hematoxylin. ERG expression was reported as positive or negative within the specimen. Positive staining of endothelial cells in specimens served as built-in control for the assay. ERG protein expression was also correlated with clinico-pathologic features.

\section{Fluorescent In-situ Hybridization (FISH) Assay for detection of ERG gene rearrangements}

Dual-color interphase FISH for detecting TMPRSS2-ERG fusion status or ERG rearrangement status of chromosome 21q22.2 was analyzed by FISH break-apart assay ${ }^{12}$. Biotin-14-dCTP labeled BAC clone RP11-24A11 (red avidin-rhodamine) and digoxigenindUTP-labeled BAC clone RP11-137J13 (green fluorescein-tagged anti-DIG antibody) were used in FISH assay as described previously ${ }^{26,27}$.

\section{Results}

Of the original 51 specimens, 30 (Table 1) were evaluable for identifying the incidence of ERG positivity (Figure 1). Specimens were not included if they had prior hormonal treatment (13 patients), or the specimen did not contain any tumor (8 patients). ERG 
positive tumors were present in 8 of 30 cases $(27 \%)$ and one tumor specimen exhibited rare ERG positive cells. None of the benign glands were positive for ERG supporting previous studies on complete specificity of ERG oncoprotein for detection of tumors cells in prostate. There were no primary Gleason 5 patterns in the ERG positive cohort (Table 2). All of the tumors that were positive for ERG were confirmed to have ERG rearrangement by FISH. Three specimens demonstrated collision tumors where there was a distinct margin within a tumor of glands staining positive for ERG and those that did not. Of 27 evaluable specimens with clinical data, ERG expression had no significant association with any of the clinicopathological parameters (data not shown).

Table I. Baseline characteristics of the 30 evaluable prostate tumor specimens.

\begin{tabular}{cc}
\hline Variable & Number of prostate tumor specimens \\
\hline N total & $30(100 \%)$ \\
Gleason sum & $\mathrm{N}(\%)$ \\
6 & $11(37)$ \\
$3+4$ & $8(27)$ \\
$4+3$ & $4(13)$ \\
8 & $7(23)$ \\
9 and 10 & 0 \\
ERG IHC positive & $8(27)$ \\
ERG IHC negative & $22(73)$ \\
\hline
\end{tabular}

Table 2. Heat map illustrating the correlation of ERG positive specimens with primary Gleason score.

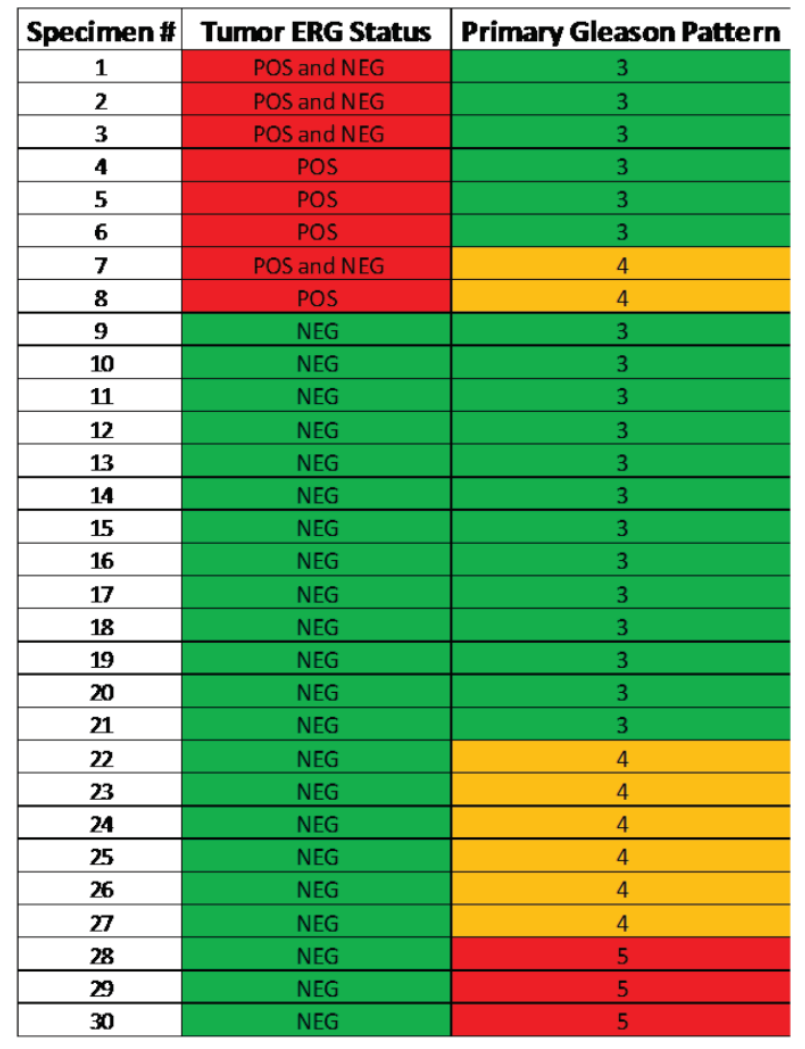

Note that none of the primary pattern Gleason 5 lesions were ERG positive.
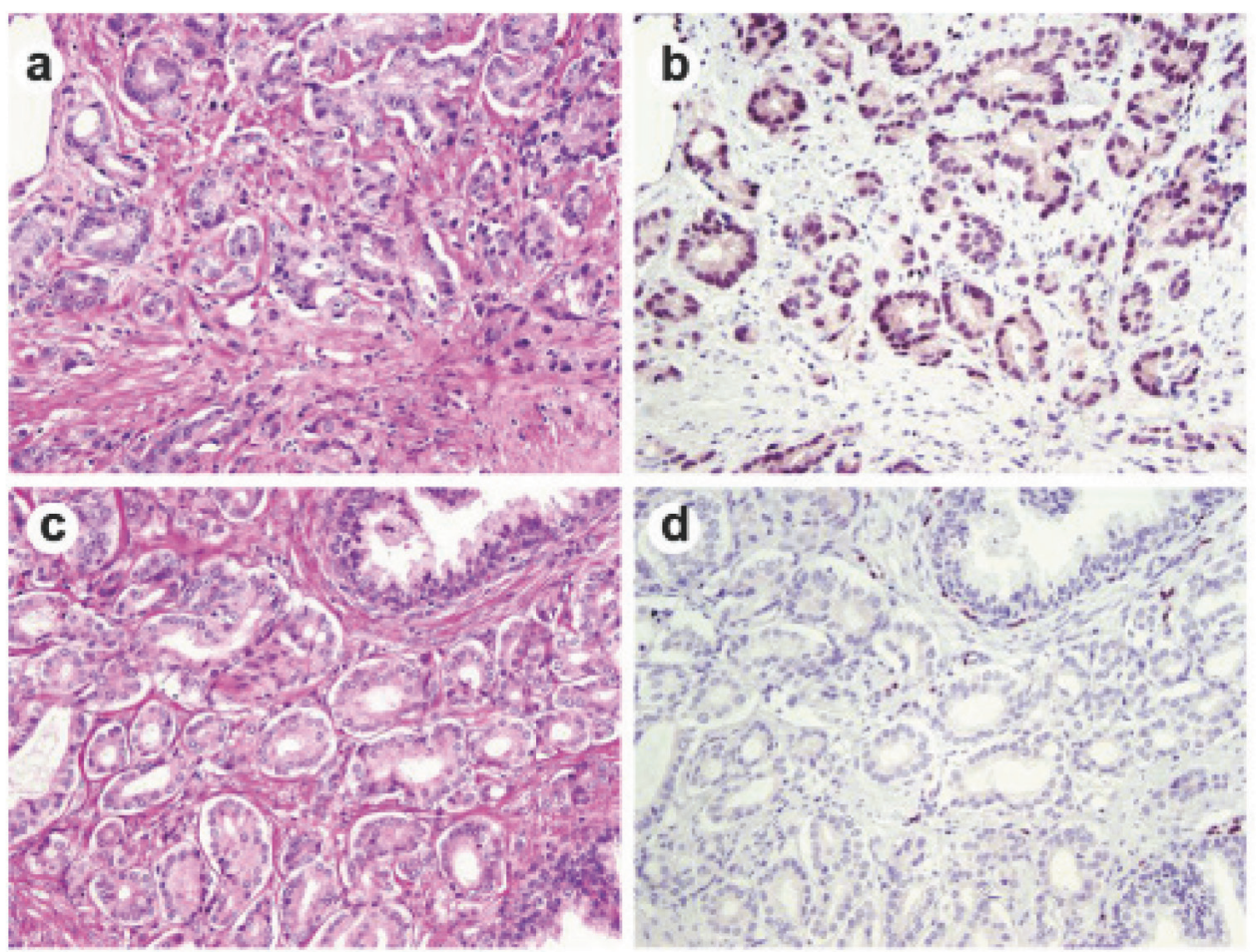

Fig I. ERG immunohistochemical staining in prostate tissue. Representative consecutive prostate tumor sections were stained by H\&E (a and c) and by ERG-MAb mouse monoclonal antibody ( $b$ and $d$ ). Nuclear staining of the tumor epithelium is apparent in ERG positive tumors (b), and missing in ERG negative tumors (d). 


\section{Discussion}

This study provides first glimpse into the ERG gene and protein alterations in $\mathrm{CaP}$ from India. As noted before $\mathrm{CaP}$ associated ERG alterations are highest in men of European ancestry and lowest in Asians men with intermediate frequencies noted for African Americans. Although larger studies are needed, ERG frequencies in Indian CaP are similar to Asian frequencies. Further, there are no studies of ERG in CaP from Africa till date. Clearly there is need for careful evaluations of the CaP associated ERG alterations in the global context as this cancer gene is the most common CaP gene defect in Western countries and it is a promising therapeutic and biomarker target.

While there is hardly any information available on $\mathrm{CaP}$ associated somatic gene alterations in Indian population, there are numerous studies of association of single nucleotide polymorphisms (SNP). Kesarwani et al. demonstrated single nucleotide polymorphisms in tumor necrosis factor alpha may influence $\mathrm{CaP}$ risk, stage and progression in the North Indian population ${ }^{28}$. Another genetic factor that has been studied among several populations is the glutathione S-transferase gene (GSTM1, GSTT1 and GSTP1). In the North Indian population, there was a higher risk of $\mathrm{CaP}$ in men with the GSTP1-313 G, GSTM1 and GSTT1 alleles. A combination of the GST genotypes further increased risk of $\mathrm{CaP}^{29}$. The results found here are similar to those in Japan, but differ from prior studies looking at Austrian, German and American populations ${ }^{30-33}$. In contrast to these studies, the widely studied SNPs on chromosome 8q24 showing association with risk of $\mathrm{CaP}$ in Western countries were also found in Indian population ${ }^{34}$.

Genetics, diet, lifestyle and environmental conditions are all likely affecting the incidence of any cancer including $\mathrm{CaP}$ among different demographics. The multifactorial influences involved in the development and progression of $\mathrm{CaP}$ represent a complex puzzle. The CaP associated ERG gene alteration is a potentially important piece in this puzzle that may guide us to differences of underlying biology of $\mathrm{CaP}$ among different demographics. These observations will have a significant impact in the management of $\mathrm{CaP}$ in different populations as we begin to develop the biological stratification of $\mathrm{CaP}$.

\section{Acknowledgements}

A research grant from National Cancer Institute R01CA162383 (S. S.) and CPDR program fund HU0001-10-2-0002 supported this work. The authors would like to thank Yongmei Chen for statistical support.

\section{Disclaimer}

The views expressed in this paper are those of the authors and do not reflect the official policy of the Department of the Army, Department of Defense or the U.S. Government.

\section{Competing Interests}

The authors have declared that no competing interest exists.

\section{References}

1. Siegel R, Naishadham D, Jemal A. Cancer statistics, 2013. CA Cancer J Clin. $2013 ; 63(1): 11-30$.

2. [Internet] Ferlay JSH, Bray F, Forman D, Mathers C and Parkin DM. GLOBOCAN 2008 v1.2, Cancer Incidence and Mortality Worldwide: IARC CancerBase No 10. http://globocan.iarc.fr.

3. Gronberg H. Prostate cancer epidemiology. Lancet. 2003;361(9360):859-864.

4. Sim HG, Cheng CW. Changing demography of prostate cancer in Asia. Eur J Cancer. 2005;41(6):834-845.

5. Mosquera JM, Mehra R, Regan MM, et al. Prevalence of TMPRSS2-ERG fusion prostate cancer among men undergoing prostate biopsy in the United States. Clin Cancer Res. 2009;15(14):4706-4711.

6. Gopalan A, Leversha MA, Satagopan JM, et al. TMPRSS2-ERG gene fusion is not associated with outcome in patients treated by prostatectomy. Cancer Res. 2009;69(4):1400-1406.

7. Lapointe J, Kim YH, Miller MA, et al. A variant TMPRSS2 isoform and ERG fusion product in prostate cancer with implications for molecular diagnosis. Modern Pathology. 2007;20(4):467-473.

8. Perner S, Demichelis F, Beroukhim R, et al. TMPRSS2:ERG fusion-associated deletions provide insight into the heterogeneity of prostate cancer. Cancer Res. 2006;66(17):8337-8341.

9. Rajput AB, Miller MA, De Luca A, et al. Frequency of the TMPRSS2:ERG gene fusion is increased in moderate to poorly differentiated prostate cancers. J Clin Pathol. 2007;60(11):1238-1243.

10. Tu JJ, Rohan S, Kao J, Kitabayashi N, Mathew S, Chen YT. Gene fusions between TMPRSS2 and ETS family genes in prostate cancer: frequency and transcript variant analysis by RT-PCR and FISH on paraffin-embedded tissues. Modern Pathology. 2007;20(9):921-928.

11. Yoshimoto M, Joshua AM, Cunha IW, et al. Absence of TMPRSS2:ERG fusions and PTEN losses in prostate cancer is associated with a favorable outcome. Modern Pathology. 2008;21(12):1451-1460.

12. Tomlins SA, Rhodes DR, Perner S, et al. Recurrent fusion of TMPRSS2 and ETS transcription factor genes in prostate cancer. Science. 2005;310: 644-648.

13. Petrovics G, Liu A, Shaheduzzaman S et al. Frequent overexpression of ETS-related gene-1 (ERG1) in prostate cancer transcriptome. Oncogene. 2005;24: 3847-3852.

14. Rubin MA, Maher CA and Chinnaiyan AM. Common gene rearrangements in prostate cancer. J Clinic Oncol. 2011;29: 3659-3668.

15. Sreenath TL, Dobi A, Petrovics G et al. Oncogenic activation of ERG: A predominant mechanism in prostate cancer. J Carcinogen. 2011;10: 37.

16. Dobi A, Sreenath T, Srivastava S. Androgen dependent oncogenic activation of ETS transcription factors by recurrent gene fusions in prostate cancer: Biological and Clinical Implications. In: Wang Z, ed. Androgen-Responsive Genes in Prostate Cancer. New York, USA: Springer. 2013.

17. Sun C, Dobi A, Mohamed A, et al. TMPRSS2-ERG fusion, a common genomic alteration in prostate cancer activates C-MYC and abrogates prostate epithelial differentiation. Oncogene. 2008;27: 5348-5353.

18. Brenner JC, Ateeq B, Li Y, et al. Mechanistic rationale for inhibition of poly(ADP-ribose) polymerase in ETS gene fusion-positive prostate cancer. Cancer Cell, 2011;19: 664-78.

19. Shao L, Tekedereli I, Wang J, et al. Highly specific targeting of the TMPRSS2/ERG fusion gene using liposomal nanovectors. Clin Cancer Res. 2012;18: 6648-57. 
20. Rosen P, Pfister D, Young D, et al. Differences in frequency of ERG oncoprotein expression between index tumors of Caucasian and African American patients with prostate cancer. Urology. 2012 Oct;80(4):749-53.

21. Magi-Galluzzi C, Tsusuki T, Elson P, et al. TMPRSS2-ERG gene fusion prevalence and class are significantly different in prostate cancer of Caucasian, African-American and Japanese patients. The Prostate. 2011;71(5):489-497.

22. Petrovics G, Liu A, Shaheduzzaman S, et al. Frequent overexpression of ETS-related gene-1 (ERG1) in prostate cancer transcriptome. Oncogene. 2005;24(23):3847-852.

23. Miyagi Y, Sasaki T, Fujinami K, et al. ETS family-associated gene fusions in Japanese prostate cancer: analysis of 194 radical prostatectomy samples. Modern Pathology. 2010;23(11):1492-1498.

24. Mao X, Yu Y, Boyd LK, et al. Distinct genomic alterations in prostate cancers in Chinese and Western populations suggest alternative pathways of prostate carcinogenesis. Cancer Res. 2010;70(13):5207-5212.

25. Furusato B, van Leenders GJ, Trapman J et al. Immunohistochemical ETS-related gene detection in a Japanese prostate cancer cohort: diagnostic use in Japanese prostate cancer patients. Pathol Int. 2011;61: 409-14.

26. Furusato B, Tan SH, Young D, et al. ERG oncoprotein expression in prostate cancer: clonal progression of ERG-positive tumor cells and potential for ERG-based stratification. Prostate Cancer Prostatic Dis. 2010 Sep;13(3):228-37.

27. Perner S, Demichelis F, Beroukhim R, et al. TMPRSS2:ERG fusion-associated deletions provide insight into the heterogeneity of prostate cancer. Cancer Res. 2006;66(17):8337-41.

28. Kesarwani P, Mandhani A, Mittal RD. Polymorphisms in tumor necrosis factor-A gene and prostate cancer risk in North Indian cohort. J Urol. 2009;182(6):2938-2943.

29. Srivastava DS, Mandhani A, Mittal B, Mittal RD. Genetic polymorphism of glutathione S-transferase genes (GSTM1, GSTT1 and GSTP1) and susceptibility to prostate cancer in Northern India. BJU Int. 2005;95(1):170-173.

30. Gsur A, Haidinger G, Hinteregger S, et al. Polymorphisms of glutathione-S-transferase genes (GSTP1, GSTM1 and GSTT1) and prostate-cancer risk. Int J Cancer. 2001;95(3):152-155.

31. Murata M, Shiraishi T, Fukutome K, et al. Cytochrome P4501A1 and glutathione S-transferase M1 genotypes as risk factors for prostate cancer in Japan. Jpn J Clin Oncol. 1998;28(11):657-660.

32. Rebbeck TR, Walker AH, Jaffe JM, White DL, Wein AJ, Malkowicz SB. Glutathione S-transferase-mu (GSTM1) and -theta (GSTT1) genotypes in the etiology of prostate cancer. Cancer Epidemiol Biomarkers Prev. 1999;8(4 Pt 1):283-287.

33. Steinhoff C, Franke KH, Golka K, et al. Glutathione transferase isozyme genotypes in patients with prostate and bladder carcinoma. Arch Toxicol. 2000;74(9):521-526.

34. Tan YC, Zeigler-Johnson C, Mittal RD, et al. Common 8q24 sequence variations are associated with Asian Indian advanced prostate cancer risk. Cancer Epidemiol Biomarkers Prev. 2008;17(9):2431-5. 